\title{
LIMITES E POSSIBILIDADES DO TRADUTOR-INTÉRPRETE DE LIBRAS EDUCACIONAL E O SURDO
}

\section{ARTIGO ORIGINAL}

VALIM, Eliangela Nascimento ${ }^{1}$

RAGGI, Désirée Gonçalves ${ }^{2}$

VALIM, Eliangela Nascimento. RAGGI, Désirée Gonçalves. Limites e possibilidades do tradutor-intérprete de libras educacional e o surdo. Revista Científica Multidisciplinar Núcleo do Conhecimento. Ano 05, Ed. 06, Vol. 02, pp. 106-130. Junho de 2020. ISSN: 2448-0959, Link de acesso: https://www.nucleodoconhecimento.com.br/educacao/limites-epossibilidades

\section{RESUMO}

Foi investigado o papel do Tradutor Intérprete em Libras (TILS) nas escolas com alunos surdos não alfabetizados em Libras, para analisar os limites e possíveis soluções que estes profissionais para tal problemas. Para verificar esta questão, foram levantados dados por meio de questionários entregues a 8 TILS e 5 professores regentes (PR) de uma escola da rede estadual em Vitória - Espírito Santo. Com a análise dos dados foi possível verificar que os TILS utilizam formas alternativas para comunicar-se com os alunos em questão e promover a mediação entre eles os PR. Percebeu-se ainda que há um grande problema de comunicação entre os TILS e os demais profissionais da escola, acarretando prejuízo aos alunos. Viu-se a necessidade de mudanças quanto a equipe pedagógica da escola afim de beneficiar os alunos.

\footnotetext{
${ }^{1}$ Mestrado em ciências, tecnologia e Educação.

2 Doutorado em educação.
} 
Palavras-chaves: Tradutor-Intérprete de Libras (TILS), aprendizagem de alunos surdos, Educação Especial, Ferramentas Educacionais Alternativas.

\section{INTRODUÇÃO}

De acordo com Mantoan (2011) a educação é um direito humano, fundamental, e, portanto, deve ser colocado à disposição de todos. No entanto, a educação de surdos requer um olhar diferenciado, pois sua inclusão, na maioria das vezes, não se concretiza na prática. A educação de surdos vem ao longo do tempo sendo debatida, pois ainda hoje, a sociedade considera os surdos sujeitos incapazes de aprender, quando deveria perceber que essas pessoas tem grande potencial, pois são inteligentes e capazes de assimilar novos saberes, de atuar de forma autônoma e serem felizes fazer parte ativa nos espaços sociais. Tem potencial para contribuir com a sociedade. Ainda vivemos em uma sociedade que se encontra adaptada ao público ouvinte e ao se deparar com a comunidade surda, encontra grande dificuldade de comunicação e aceitação.

O surdo percebe o mundo de forma diferenciada dos ouvintes, através de uma experiência visual, e faz uso de uma linguagem específica, a Língua de Sinais. Esta língua é, antes de tudo, a imagem do pensamento dos surdos e faz parte da experiência vivida na sua própria comunidade. Nesse sentido, Quadros (2004, p. 58) esclarece que "[...] Como artefato cultural, a Língua de Sinais também é submetida a significação social a partir de critérios valorizados, sendo aprovada como sistema de linguagem rica e independente". Portanto, é importante que a sociedade compreenda e valorize essa língua como elemento cultural da comunidade surda e tente interagir com essas pessoas.

A demanda dos alunos surdos não alfabetizados em libras requisita mais diálogo entre os Tradutores - Intérpretes Educacionais, os professores do ensino regular, e a gestão escolar, visto que a forma de conceber a aprendizagem desses sujeitos não será equivalente às estratégias aplicadas com alunos surdos alfabetizados em Libras. Rodriguês e Beer (2016, p.661) corroboram com essa ideia ao lembrarem que: "[...] é importante considerarmos a questão da diferença linguística. Portanto, falar de 
educação inclusiva para surdos é tratar inevitavelmente, das questões sociais, culturais, e políticas que envolvem as línguas".

Nesse sentido, os autores revelam que há questões que estão intrinsicamente ligadas ao uso da Língua de Sinais, porém devemos nos atentar também para a necessidade de conscientizar os agentes da escola, bem como os pais e aos alunos e que ainda não foram alfabetizados em Libras, sobre os riscos de se fortalecer a situação de marginalizados, se não forem tomados os devidos cuidados e precauções na medida em que esses sujeitos permanecem não alfabetizados em Libras.

Tais premissas se coadunam com as ideias de estudiosos do tema, quando consideraram a questão da para alcançarmos mais justiça social. Por isso se faz tão importante a capacitação e participação dos profissionais das escolas de ensino regular. Afinal, é responsabilidade das instituições educativas criar estratégias pedagógicas para que todos nos tornemos cidadãos críticos e participativos na sociedade. Assim os cidadãos surdos não podem estar ausentes desse processo, pois tem o direito garantido por lei de ter uma educação igualitária e inclusiva. Portanto, sua vida acadêmica e profissional deve ser construída por meio da escola.

Há muito que se conquistar pela categoria de profissionais que atuam na área de libras a fim de que possam obter ferramentas e meios para aprimorar o processo de ensino de pessoas surdas. Tais recursos deverão auxiliar na construção do conhecimento de alunos surdos não alfabetizados em libras e servirão de apoio para a comunicação entre professores regentes, os alunos surdos e os alunos ouvintes.

Neste contexto neste trabalho objetivou-se analisar quais são os limites e possibilidades do Tradutor- Intérprete de Língua de Sinais no processo de ensino de alunos surdos e não alfabetizados em Libras.

\section{MÉTODOS}

Esta pesquisa é um estudo de caso que de acordo com Gil (2006, p.138) "[...] referese a um indivíduo num contexto definido". Porém segundo este mesmo autor este 
conceito torna-se amplo quando o alvo de estudo, deixa de ser voltado para um só indivíduo e passa a ser centrado em grupos sociais ou em um pequeno grupo, como é o caso desta pesquisa.

Ainda segundo Gil (2006, p.139) sobre o estudo de caso coletivo: "É aquele cujo propósito é o de estudar características de uma população. Eles são selecionados porque se acredita que, por meio deles, torna-se possível aprimorar o conhecimento acerca do universo a que pertencem."

O presente trabalho é classificado como estudo de caso coletivo, pois a investigação se concentrou em um grupo de profissionais de uma mesma área dos quais se extraíram informações que levaram a uma posterior reflexão de sua formação e forma de atuação (GIL, 2006).

Trata-se também de pesquisa de natureza qualitativa e cunho descritivo, pois buscou compreender como os TILS concebem a prática da educação de surdos não alfabetizados, relatando seus limites e possibilidades sobre essa questão.

A pesquisa foi realizada na EMEF da rede Municipal de Vitória/ES, Suzete Cuendet, localizada em Maruípe na cidade de Vitória-ES, onde existem alunos surdos em todas as séries do ensino fundamental. Tal escola apresenta sala de recursos, também chamada de sala do Atendimento Educacional Especializado (AEE), e sala de Libras (local onde são ministradas as aulas de Libras). Este fator contribui grandemente para as aplicações de questionários e visto que, há uma concentração de profissionais TILS facilitando assim a coleta dos dados.

Os sujeitos desta pesquisa serão profissionais Tradutores - Intérpretes de Libras, que atuam no âmbito educacional e professores regentes que atuam no contexto escolar do aluno surdo.

As informações foram coletadas por meio de questionários abertos que foram aplicados a TILS e professores regentes, respectivamente, com o intuito de realizar um levantamento acerca da formação dos TILS que atuam juntamente com os alunos surdos e conhecer as opiniões desses sujeitos sobre o papel do Tradutor- Intérprete 
de Libras dentro do convívio educacional e social e o papel da escola em relação a inclusão do aluno surdo, não alfabetizado.

Segundo Marconi e Lakatos (2002, p. 98), "Questionário é um instrumento de coleta de dados constituído por uma série ordenada de perguntas, que devem ser respondidas por escrito e sem a presença do entrevistador".

Juntamente com o questionário foi enviado um informativo esclarecendo sobre o que se tratava a pesquisa e a importância da participação da mesma. Neste estudo a análise de dados é do tipo qualitativa. As respostas dos questionários serão analisadas visando o levantamento das informações pertinentes a pesquisa.

\section{RESULTADOS}

Os oito TILS participantes da pesquisa possuem formações em pedagogia, Letras Libras e Letras Português. A maior parte deles possui Pós-Graduação em Educação Inclusiva ou Especial e cursos específicos na área de Tradução e Intérprete em Línguas de Sinais. Atuam na área da educação em períodos que variam de 1 a 10 anos como TILS educacionais.

No cotidiano educacional constatamos que existem alunos surdos não alfabetizados em Libras, na rede regular de ensino, e que não se tem uma orientação concreta de como se deve trabalhar com esse público. Nesse contexto, estão inseridos os profissionais TILS, cuja função é fazer essa mediação melhorando a comunicação entre o professor regente, de forma que o aluno surdo possa compreender e aprender os conteúdos ministrados.

Para dar conta do objetivo proposto neste estudo, buscou-se compreender quais são os limites, possibilidades e dificuldades enfrentadas pelos TILS em um ambiente escolar onde se encontram alunos surdos não alfabetizados em Libras.

Mediante as opiniões dos entrevistados, pode-se observar que quando os profissionais TILS se deparam com alunos não alfabetizados em Libras os mesmos 
se veem frustrados, desapontados e mesmo indignados por verem que o educando não foi alfabetizado em sua própria língua.

Vemos isso enfatizado na fala do TILS 4: "Eu fico frustrado, porque como pode a essa altura, ainda nos depararmos com alunos surdos sem saber a sua própria língua, é um absurdo em minha opinião". E é possível identificar na fala do TILS 8: "Eu fico triste, porque, ainda vemos alunos que não sabem Libras, isso desanima a gente como profissional."

Esses profissionais revelam em suas falas, o desânimo diante da ausência de alfabetização em Libras. Tal constatação gera uma sensação de impotência. Esse fenômeno tem uma explicação: muitos são filhos de pais ouvintistas e, não sendo alfabetizados em Libras, acabam fazendo uso de gestos corriqueiros para se comunicarem com a família. Tal situação contrasta com os estudos de Quadros (2004) quando aborda a importância do convívio e interação social para o desenvolvimento da linguagem. Se as crianças surdas não convivem com pessoas que sinalizam, dificilmente irão aprender a se comunicar por meio da Libras, e este fato pode promover uma dificuldade na interação entre ele, o Intérprete e o professor regente.

Neste contexto, os pais têm um papel muito importante no aprendizado de seus filhos, como aponta Quadros (2008):

Quando a criança surda tiver a chance de, no início do seu desenvolvimento, contar com pais dispostos a aprender a língua de sinais, com adultos surdos, com colegas surdos, quando ela narrar em sinais e tiver escuta em sinais, a dimensão do seu processo educacional será outra (QUADROS, 2005, p.10).

Percebe-se então a importância da participação da família no processo escolar dos alunos, pois sem a sua colaboração, o aprendizado da Libras pode ficar comprometido e ocorrerem prejuízos na apreensão de conteúdos para formação desses sujeitos. Contudo, a escola pode intervir promovendo o encaminhamento desses alunos surdos 
não alfabetizados em Libras às instituições especializadas, a fim de buscar apoio para sanar este déficit, já que sem a Libras a relação escolar do aluno é prejudicada.

É possível contatar pela manifestação do TILS 3, que o profissional pode fazer a diferença no sentido de buscar soluções para minimizar as dificuldades decorrentes da não alfabetização em Libras, informando à equipe pedagógica sobre essa necessidade e alertar para o risco da insuficiente aprendizagem que o aluno terá sem habilidade para interpretar e compreender os conteúdos propostos.

Mediante essa situação, com um aluno que não tem conhecimento linguístico na Libras, sinalizo ao setor pedagógico e a equipe docente a situação e que não haverá interpretação simultânea, pois o discente não irá conseguir acompanhar as terminologias utilizadas em sala de aula. Após dialogar com o setor pedagógico, faço uma análise exploratória com o aluno da sua percepção de mundo (anamnese), assim irá corroborar com as estratégias e escolhas que irei realizar no ato da interpretação. Dessa forma, faço a opção de utilizar recursos imagéticos de forma que o aluno irá reconhecer a imagem e o sinal (palavra) que será apresentado. Explorando sempre o conhecimento prévio do educando (Excerto questionário TILS 3).

O TILS 3 explica que busca estratégias para auxiliar a interação com o aluno. Dentre essas, podemos lançar mão dos classificadores que são uma forma de recurso imagético. Os classificadores "São elementos estruturais da Libras que não existem nas línguas orais. São formas de concordância em uma língua, ou ainda, formas representadas por configurações de mãos" (KIKUICHI et al, 2011).

Tudo isso é realizado levando-se em conta o conhecimento prévio do aluno, pois busca-se reconhecer em sua trajetória de vida, captar os conhecimentos que possui, os saberes que já assimilou, para que o recurso seja realizado de maneira focada. Nessa perspectiva, Ausubel et al. (1980, p.137) corroboram ao defender que: "Se quiséssemos reduzir a psicologia educacional em um único princípio este seria: $O$ 
fator isolado mais importante que influencia a aprendizagem é aquilo que o aprendiz já conhece. Descubra o que sabe e baseie nisso seus ensinamentos."

No entanto, esse é um exemplo de profissional pouco recorrente na realidade concreta das escolas, pois a maioria não apresenta a mesma vontade e não consegue agir da mesma forma, deixando-se vencer pelas precárias condições de comunicação em que encontram nos alunos.

Os Intérpretes sentem muita dificuldade quanto à comunicação formal com os alunos surdos não alfabetizados em Libras, dentre os oito profissionais abordados sete deles confirmaram essa dificuldade.

O TILS 3 demonstra uma consciência mais ampliada a respeito das consequências que essa barreira da comunicação pode trazer ao revelar que esses alunos terão "[...] dificuldade de compreensão e interpretação de mundo e sentido, dificuldade de aprendizagem, entre outros" (Excerto questionário TILS 3), quando não interpretam a Libras, no processo ensino aprendizagem.

Verifica-se, portanto, que os problemas de comunicação podem acarretar adversidades na formação dos alunos, quando sua interação com o meio social está prejudicada pela não alfabetização. Nesse sentido, Vygotsky (1983) assinala que o desenvolvimento humano se dá no âmbito social, por meio da interação social, então se o indivíduo não se comunica adequadamente, seu desenvolvimento fica prejudicado.

Apesar das dificuldades mencionadas anteriormente os profissionais participantes da pesquisa utilizam outros meios para se comunicarem com os alunos surdos não alfabetizados. E para isso precisam contar com as mais diversas formas de comunicação não verbal e, em sua maioria, relatam que utilizam objetos visualmente compreensíveis.

De acordo com o TILS 2: "Para me comunicar vale tudo: imagens em celular, teatro, mímica, desenhos, tudo que contribua para um entendimento visual”. Já quando perguntado, o TILS 5 reitera: "Faço um pouco de tudo, tento usar estratégias com este 
aluno, mas tudo voltado para o visual”. E à fim de concluir a análise, o TILS 6 disse que: "eu tento algum recurso visual, mostrar a imagem e perguntar o sinal, assim posso avaliar seu nível de conhecimento".

Visando superar esta dificuldade, citaram que "seria de muita ajuda a criação de um material, uma apostila", como estratégia de recurso de tradução para que fosse possível promover uma melhor comunicação e entendimento dos conteúdos ensinados em sala. Além disso dois dos TILS mencionaram a produção de um material audiovisual, "[...] creio que este recurso seria interessante [...]", porém existe uma dificuldade por parte das escolas, para a aquisição de equipamentos específicos e necessários nas escolas, e isso consiste em uma barreira para que os professores e alunos possam usufruir desse tipo de recurso.

Quando questionados sobre o papel do TILS educacional para o desenvolvimento no processo de aprendizagem do aluno surdo, a metade deles afirma ter como função somente a interpretação. Contudo, ultrapassam os limites dessa função, como pode ser visto na fala do TILS 1 e 3 . Esses profissionais podem fazer muita diferença na vida escolar do aluno surdo, sem ter que necessariamente ensinar o conteúdo ministrado em aula.

O TILSE transmite em libras as informações passadas pelo professor regente; transmite em português as informações passadas pelos alunos surdos; contribui no desenvolvimento do aluno; estimula a comunicação entre os alunos surdos e os alunos ouvintes; etc (Excerto questionário TILS 1).

Fundamental! Pois, ele é o mediador linguístico entre surdos e ouvintes e outros pares e não pares linguísticos no processo de comunicação e/ou enunciação de um discurso. O Tradutor Interprete de Libras / Língua Portuguesa - Educacional TILSP(E), corrobora diretamente no ensino e aprendizagem do aluno, pois, proporcionando a autonomia do aluno e empoderamento linguístico do mesmo, já que, esse profissional é a ponte entre duas línguas (Excerto questionário TILS 3). 
Nessa proposição, Bakhtin (2006) contribui ao ressaltar que o papel do intérprete não é somente passar uma informação em Libras para o aluno, mas sim promover a produção do sentido acerca dos conhecimentos contemplados em sala de aula, para que $o$ aluno possa ter uma melhor compreensão do contexto abordado.

Lacerda (2009) também corrobora com essa discussão ao ressaltar a importância do trabalho em conjunto entre os TILS e os professores regentes, pois como diz:

A sala de aula tradicionalmente se constitui como um lugar no qual o professor ensina e a criança aprende. Com a entrada do TILS no espaço educacional, acrescenta-se um terceiro elemento que estará lá não só para interpretar da LIBRAS para o português e do português para a LIBRAS, mas também para mediar os processos discursivos entre professor e aluno, almejando a aprendizagem do aluno (LACERDA, 2009, p. 39).

Nesse sentido, destaca-se a importância dessa interação para o processo de ensinoaprendizagem do aluno surdo. Porém mediante a análise das opiniões dos TILS, pode-se constatar que percebem que há certo desinteresse por parte dos regentes em saber Libras. Então, percebe-se que os docentes ainda não compreendem a necessidade de se apropriarem do básico da língua dos surdos, e sua importância para melhorar sua interação com os mesmos.

Os professores regentes não são obrigados a saber Libras, não é papel do deles se comunicarem com seus alunos surdos pela Língua de Sinais, mas o conhecimento de Libras é importante, porque quando os surdos aprendem português, usam estruturas da língua de sinais na língua escrita. Portanto, seria de grande valia que os professores aprendessem Libras para que, ao ensinar português, ele consiga compreender como funciona a lógica de comunicação do surdo. Nos ambientes regulares de ensino, com frequência, existem surdos contudo, os professores não recebem treinamentos que os capacitem para ministrar aulas para alunos surdos. 
Considerando a perspectiva da educação inclusiva, o professor deveria estar devidamente preparado para atuar na diversidade, para que possa compreender as diferenças inerentes à humanidade, e assim, valorizar as potencialidades individuais de cada aluno. Nesse sentido, Silva e Rodrigues (2011) pontuam que:

[...] existe uma distinção profunda entre simplesmente aceitar e respeitar, e o processo de compreensão da diferença, que demanda das pessoas disposição e compromisso para trabalhar com o ser humano no sentido de contribuir com o desenvolvimento de um sujeito social, histórico e politicamente consciente. Não se trata de apenas acolher a diversidade, mas de compreender sua produção e complexidades na realidade de cada sujeito (SILVA E RODRIGUES, 2011, p.62).

Os professores regentes participantes da pesquisa reconhecem que não sabem Libras e se sentem perdidos quando se deparam com um aluno surdo em sala. Consideram que, para que esta questão pudesse ser amenizada, deveriam aprender Libras ou pelo menos o básico da língua, a fim de obter uma melhor interação com os alunos surdos.

A escola poderia tentar solucionar esta questão das barreiras de comunicação entre o professor regente e o aluno surdo promovendo uma parceria com Estado e Município, para articular formações específicas para a aprendizagem da Libras, entre os docentes. Desta forma eles teriam a oportunidade de aprender os níveis Básico, o Intermediário e o curso Avançado da Libras, o que tornaria a comunicação como os alunos surdos mais eficiente.

Para Mantoan (2011):

A formação continuada de professores, visando a inclusão de todos os alunos e o acesso deles ao Ensino superior, precisava levar em conta princípios de base que os instrumentalizem para a organização do ensino e a gestão da classe, bem como princípios éticos, políticos e filosóficos que permitam que esses profissionais compreenderem o 
papel deles e da escola frente ao desafio de formar uma nova geração capaz de responder as demandas do nosso século, no que consiste a educação (MANTOAN, 2011, p.141).

Essa formação, certamente, os professores melhorariam sua interação com os alunos surdos alfabetizados ou não, em Libras.

Além das questões abordadas, surgiu outra de extrema importância para o desenvolvimento das atividades dos TILS e professores regentes no processo de ensino-aprendizagem do aluno surdo, que foi nas expressa pela TILS 8, a respeito de uma fase fundamental no processo, o planejamento coletivo: "O mais complicado para mim é a questão do $\mathrm{PL}$, nós não temos direito de sentar e de ver o conteúdo com antecedência."

Esta questão é muito preocupante, pois segundo Libâneo (2013):

O planejamento escolar é uma tarefa docente que inclui tanto a previsão das atividades didáticas em termos de sua organização e coordenação em face dos objetivos propostos, quanto a sua revisão e adequação no decorrer do processo de ensino. O planejamento é um meio para se programar as ações docentes, mas é também um momento de pesquisa e reflexão intimamente ligado à avaliação (LIBÂNEO, 2013, p.245).

Havendo a possibilidade de dispor um espaço/tempo na carga horária do TILS, provavelmente a articulação entre esses dois personagens seria muito mais eficiente e profícua, já que esse seria o momento propício para troca de experiências e para sanar as possíveis dificuldades apresentadas por ambas as partes. Essa falta de articulação compromete o trabalho dos dois profissionais e termina prejudicando o desenvolvimento educativo do aluno surdo.

Não cabe ao TILS educacional o papel de ensinar da Libras em escolas de ensino regular. Porém, muitos profissionais da educação não têm esse entendimento e atribuem aos TILS a função de ministrar aulas de Libras aos alunos surdos que não sabem gestualizar. Esta função é do professor Surdo, que é o professor de Libras. 
Para dar esse tipo de apoio, a escola também pode lançar mão do Centro de atendimento ao Surdo (CAS), do Espírito Santo. Apesar de saber Libras, os intérpretes não têm a formação necessária para ensinar a língua, assim como observado na fala do TILS 3:

Acredito que é um desafio. Pois, para ensinar uma língua requer uma formação específica e recursos didático que não competem a prática de interpretação. Todavia, como tenho formação na área de ensino, vejo facilidades para fazer essa proposta, pensando no aluno e no contexto que estou inserido (Excerto questionário TILS 3).

Por ser um personagem relativamente novo, no campo da educação brasileira, o papel do TILS I precisa ser mais bem definido e ficar mais claro para a comunidade escolar, além de requerer legislações próprias para que o mesmo tenha garantida, como direito, sua posição quanto às funções no ambiente escolar. Sobre essa temática, Lacerda (2006) considera a necessidade de:

[...] definir melhor a função do interprete educacional; figura desconhecida, nova que, com um delineamento mais adequado (direitos e deveres do intérprete, limites da interpretação, divisão do papel de interprete e de professor, relação do interprete com alunos surdo e ouvintes em sala de aula, entre outros), poderia favorecer um melhor aproveitamento deste profissional no espaço escolar (LACERDA, 2006, p.7).

$\mathrm{Na}$ escola campo desta pesquisa, essa situação acontece e isso se pode constatar no posicionamento de alguns dos professores regentes. Para o Regente 2: "o papel dele eu não sei, o que eu sei é que ele me ajuda na comunicação com os alunos surdos". Já de acordo com o Regente 4: "Ele é fundamental para ajudar o aluno surdo, mas confesso eu não sei bem suas atribuições”. E por fim, alega o Regente 5: 'O Intérprete me ajuda muito nesta questão de comunicação, porque ele tem noção da Libras isso é importante, confundimos as vezes o seu papel, isso eu reconheço." 
Ainda que desconheçam as atribuições do TILS, os docentes reconhecem sua importância para o processo de ensino de alunos surdos. Todavia, percebemos em nosso cotidiano que muitos agentes do meio escolar consideram que, pelo fato de dominarem a linguagem de sinais o TILS, têm o dever de ensinar Libras para os alunos surdos, mas isso não é sua atribuição. Fato que os enquadrariam em desvio de função, já que estes profissionais têm seu campo de atuação definido. Tais situações revelam a necessidade da implementação de políticas públicas e diretrizes que regulamentem as práticas desses profissionais no contexto escolar.

Mediante aos argumentos expostos verifica-se que os TILS tem sua atuação limitada e passam por grandes desafios no contexto escolar, a saber: suas funções não são bem definidas, os outros sujeitos que atuam na escola desconhecem o seu verdadeiro papel. Além disso, enfrentam o desafio de promover uma comunicação eficaz e a mediação dos conteúdos ensinados pelos professores aos alunos surdos, que desconhecem a Libras.

Consideramos que essa dificuldade poderia ser amenizada com materiais de apoio que ajudariam a promover uma melhor comunicação entre os alunos surdos não alfabetizados em Libras e os demais agentes do campo escolar. Nessa direção, os sujeitos investigados apontaram a necessidade de materiais instrucionais inteiramente visuais, de fácil utilização pelos intérpretes, como solução para facilitar a assimilação dos conhecimentos estudados pelos alunos.

Considerando essa prerrogativa, ao final deste trabalho constato que é necessário a confecção de um material norteador (Produto Educacional), que consistiria em um Manual Pedagógico desenvolvido para servir de apoio que poderá auxiliar os profissionais durante sua prática de mediação e assim proporcionar um melhor ensino aos alunos surdos não alfabetizados em Libras.

\section{CONSIDERAÇÕES FINAIS}

Foi possível constatar que existem três agentes importantes no processo de ensinoaprendizagem do sujeito surdo. Os primeiros são os pais do aluno, pois se os mesmos, 
quando ouvintistas, não procuram promover uma interação da criança surda com outros surdos ao longo da infância para que eles possam aprender a Libras, a criança passa a fase de aquisição do processo linguístico sem aprender a sua primeira língua (Libras). Este momento é crucial, pois se a criança só se comunicar com gestos desconectados da Libras, os mesmos não terão um desenvolvimento escolar adequado. Neste contexto as escolas da rede Estadual e Municipal precisam ter em seu quadro de funcionários a presença do professor de Libras para que o mesmo possa ensinar a Língua de Sinais no turno ou mesmo no contra turno de estudo do discente. Além disso, as escolas podem encaminhar os alunos para o CAS, para que possam ter um melhor aproveitamento do ensino da Libras e possam estar em contato com a língua, durante um tempo maior.

O Segundo agente é o Tradutor Intérprete este é primordial no processo de mediação entre o aluno surdo e o professor Regente. Porém prevalece um problema quando esse aluno não passou pela alfabetização em Libras, pois o Intérprete precisa contar com outros meios para que possa haver pelo menos uma comunicação básica entre eles. É nesse momento que entram artifícios que podem ajudar nesse processo. Recursos visuais são os mais usados pelos profissionais. E vemos nisso a necessidade de haver materiais que auxiliem os intérpretes em seus dia-a-dia.

O terceiro agente é o professor regente, que poderia ampliar sua consciência quanto à necessidade de dominar minimamente os conhecimentos básicos da Libras para interagir melhor com os alunos Surdos. Se tal questão fosse sanada provavelmente a interação aluno surdo/TILS/professores regentes seria mais fecunda. Os sujeitos investigados consideram importante que adquiram essa habilidade.

Os TILS passam por muitas limitações quanto à medição com alunos surdos não alfabetizados em Libras, porém existem possibilidades que podem nortear seu trabalho a fim de promover uma melhor relação entre os sujeitos que compõe o ambiente escolar. Tais possibilidades podem ser assim delineadas: a escola poderia promover sua valorização; definição clara das suas atribuições, não sejam confundidas com outras funções que não Ihes cabem; a destinação de um tempo de planejamento coletivo, a fim de dialogar com os professores regentes com o intuito de 
colaborarem para o processo de ensino do aluno surdo. Além dessas ações, o desenvolvimento de materiais instrucionais poderá contribuir significativamente para esse apoio. Nesse sentido, Produto Educacional proposto poderia trazer subsídios interessantes para uma melhor comunicação entre os sujeitos mencionados neste trabalho.

\section{REFERÊNCIAS}

AUSUBEL, David Paul; NOVAK, Joseph Donald; HANESIAN, Helen. Psicologia educacional. Tradução Eva Nick. Rio de Janeiro: Interamericana, 1980.

BAKTHIN, Mikhail. Estética da Criação Verbal. Marxismo e filosofia da linguagem. Tradução de Michel Lahud e Yara Frateschi vieira. São Paulo: Hucitec, 2006.

DE QUADROS, Ronice Muller; KARNOPP, Lodenir Becker. Língua de Sinais Brasileira: Estudos Linguísticos. Porto Alegre: Artmed, 2004.

. Educação de Surdos: A Aquisição da Linguagem. Porto Alegre: Artmed. 2008.

GIL, Antonio Carlos. Como Elaborar Projetos de Pesquisa. 4aㅗ edição. São Paulo: Atlas, 2006.

KIKUICHI, Vivian Zerbinatti da Fonseca; REZENDE, Daniela Kamimura; GAHYVA, Dáphine Luciana Costa; SCUSSEL, Denise Rodovalho; MARTINS, Sandra Eleutério Campos (Org.). Processos interativos com a pessoa surda. 1 edição. São Paulo: Pearson, 2011.

LACERDA, Cristina Broglia Feitosa. Intérprete de Libras: em atuação na educação infantil e no ensino fundamental. Porto Alegre: Mediação/FAPESP, 2009.

LIBÂNEO, José Carlos. Didática. São Paulo: Cortez, 1994.

MANTOAN, Maria Teresa Eglér. O desafio das diferenças nas escolas. 4ª edição. Rio de Janeiro: Vozes, 2008. 
MARCONI, Marina de Andrade; LAKATOS, Eva Maria. Técnicas de Pesquisa. $5^{a}$ edição. São Paulo: Atlas, 2002.

RODRIGUES, Carlos Henrique.; BEER, Hana. Direitos, políticas e línguas: divergências e convergências na/da/para educação de surdos. Educação \& Realidade. Porto Alegre, v. 41, n. 3, p.661-680, 2016.

SILVA, Lázara Cristina da; RODRIGUES, Marilúcia de Menezes. Políticas públicas e formação de professores: vozes e vieses na Educação Inclusiva. In: DECHICHI, Claudia; DA SILVA, Lázara Cristina.; FERREIRA, Juliene Madureira. (Org.). Educação Especial e Inclusão Educacional: formação profissional e experiências em diferentes contextos. Uberlândia/MG: EDUFU, 2011.

VYGOTSKI, Lev Semyonovich. Interação entre aprendizado e desenvolvimento. In: VYGOTSKY, Lev Semyonovich. A Formação social da mente. São Paulo, Martins Fontes,1988.

Enviado: Março, 2020.

Aprovado: Junho, 2020. 